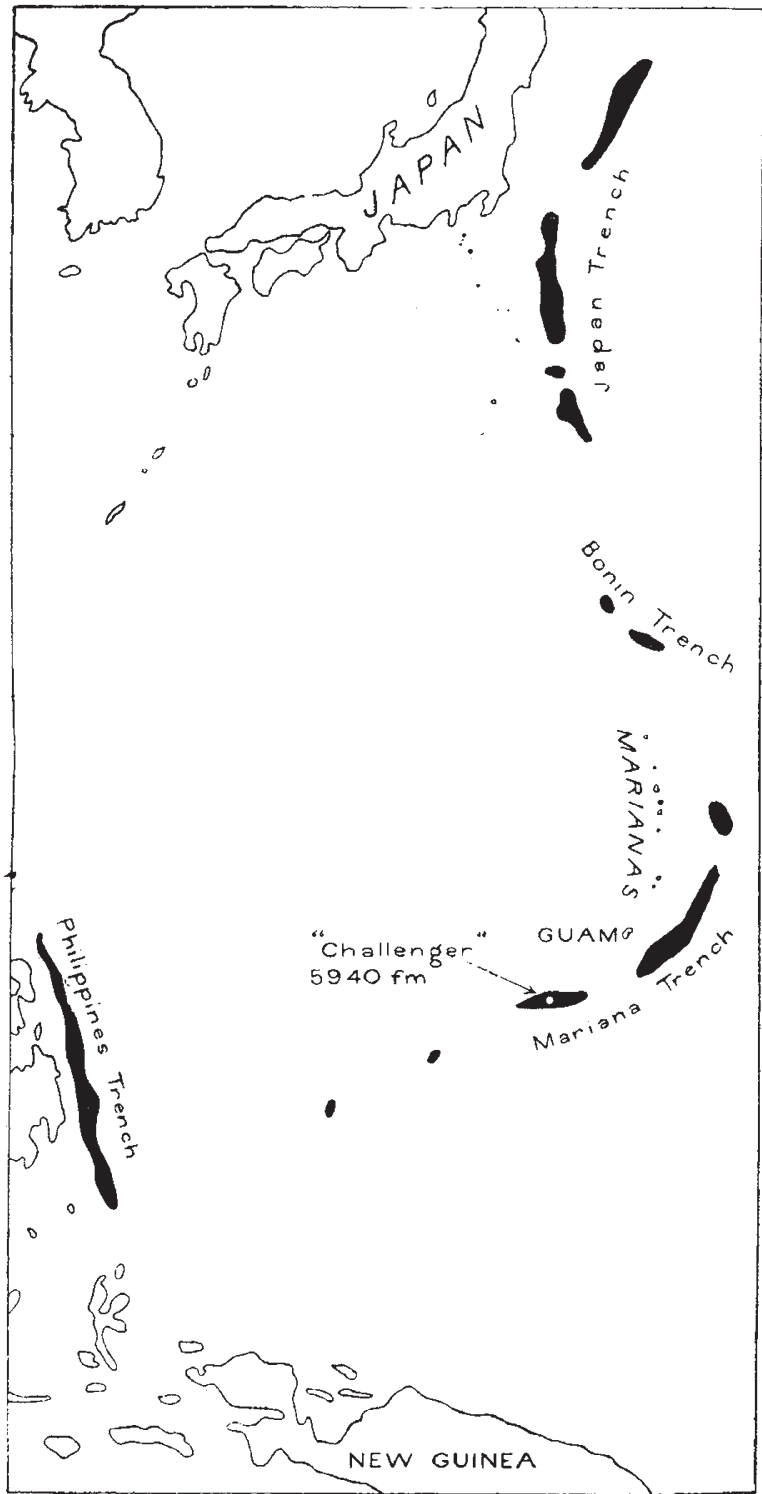

Fig. 3. The world's deepest oceanic area. Depths greater than 4,000 fathoms are shown in solid black. Challenger's deepest sounding is represented by the white spot in the Mariana Trench

by Challenger in the Mariana Trench surpasses that reported by Galathea by 177 fathoms (323 metres) and exceeds the Cape Johnson Depth by 200 fathoms (366 metres).

As regards the wire sounding, the practice of Wüst in assessing true depth from the study of the differences between wire and echo depths at different wire-angles is set out in his admirable Meteor report ${ }^{1}$. He considers that the most likely value for the true depth is the mean of the best-corrected wire and echo depths.

Both echo depths obtained during the first visit by the low-frequency method were appreciably less than the wire depth. This is surprising, because due to spurious echoes being produced by reflexion from the surrounding walls, low-frequency echo soundings in deep-sea trenches usually give values which are greater than the true depths. These echo depths, therefore, which average 5,650 fathoms (10,333 metres) can be accepted with special confidence.

If Wüst's procedure were followed, the acceptable value for the sounding first reported by Challenger would be the mean of 5,872 and 5,650 fathoms $=$ 5,761 fathoms (10,536 metres). This is greater than the Cape Johnson Depth by 21 fathoms (39 metres) and is almost identical with that obtained by Galathea.

These new Challenger soundings show that it is no longer the Philippines Trench which holds pride of place as the deepest oceanic area in the world, but the smaller Mariana Trench (Fig. 3). This region was first visited some seventy-five years ago by the illustrious namesake of the present Challenger during her famous world cruise. About fifty miles to the east of the scene of the new deep sounding, the earlier Challenger found what was the greatest depth of her cruise, namely, 4,475 fathoms $(8,184$ metres); in 1912 Sir John Murray named it the Challenger Deep ${ }^{5}$.

The U.S.S. Nero also found deep soundings in the vicinity in 1899 , and it was upon these, together with the original Challenger sounding, that Otto Krümmel based his chartlet of the Mariana Trench drawn in $1907^{\circ}$. Between 1925 and 1931 the area was extensively sounded by the Japanese naval vessels Mansyu, Kosyu, Yodo and others ${ }^{7}$, and a maximum sounding of 5,366 fathoms (9,814 metres) was obtained about ten miles away from the position of the new Challenger depth.

It is a matter of high interest to have revealed that the greatest ocean depths exist in the Mariana Trench, and it is a particular pleasure to record that the discovery was made by a British naval vessel bearing the honoured name of Challenger.

This article is published by permission of the Admiralty.

${ }^{1}$ Wüst, G., "Meteorwerk", 4, 1.

"Pinke, "Snellius" Reports, 2, Part 2, Chapter 1, Table 1, pp. 53-55 (Utrecht, 1935)

${ }^{8}$ Wüst, G., Die Erde, 3-4, 213 (1950-51).

Hess, II. H., and Buell, jun., M. W., Trans. Amer. Geophys. Union, 31 (June 1950).

${ }^{5}$ Murray, Sir John, and Hjort, J., "The Depths of the Oceans", Map. 11, p. 129 (1912).

"Krümmel, O., "Handbuch der Ozeanographie", 1, 124 (1907).

7 Sigematu, R., Record of Oceanographical Works in Japan, 5, No. 2 (Tokyo, June 1933).

\section{PROTECTIVE COATINGS OF METALS UNDER CONDITIONS OF ATMOSPHERIC CORROSION}

A JOINT meeting of the Corrosion Group of the A Society of Chemical Industry with Commission No. 4-Protection contre la Corrosion-of the Association Belge pour l'Étude, l'Essai et l'Emploi des Matériaux took place on March 14 at the Iron and Steel Institute, London, with the chairman of the Corrosion Group, Dr. W. H. J. Vernon, presiding. The Belgian Commission was represented by Prof. P. Erculisse, president of the Association, Dr. M. Van Rysselberge, secretary, and by MM. Edouard Oostens, Emile Oostens, J. Lagae, L. Frankson and D. Bermane, the Commission's investigator.

After Dr. Vernon had opened the morning session by welcoming the Belgian delegates, Prof. Erculisse read a paper summarizing the work of the Belgian Commission on protective coatings, which was formed in 1937. Research undertaken so far has been mainly 
on the formulation of paints and their performance in natural weathering tests. The first series of tests was begun in 1937 at eleven stations representing a wide range of atmospheric conditions. Some of the observations had to be abandoned because of the German occupation, during which the Commission's first investigator, M. Jeunehomme, unfortunately lost his life; but results covering ten years of exposure are now available for most of the stations. Red lead in linseed oil has proved to be the best of a number of priming paints for steel. 'This observation was confirmed by the results of more recent tests, in which only two other paints gave results comparable with those for red lead. These were a paint of zinc and zinc oxide in linseed oil and an aluminium paint in a coal tar pitch medium. Zinc chromate paints in alkyd media and chlorinated rubber paints gave only moderate results. It was also found that the durability of painting schemes was longer by up to 30 per cent on low-alloy steels containing copper, or chromium and aluminium, than on ordinary steel. Accelerated weathering tests are made in parallel with the fieldtests, using a test cycle that has been evolved from the original Gardner wheel. The breakdown of the paint film is followed by determining its hardness, adhesion, elasticity and permeability. The most recent test programme now being initiated is concerned with sixty new priming paints for steel, in which some of the newer paint-forming materials have been incorporated. The media include certain alkyds and styrenated oils; red lead, basic lead sulphate, lead cyanamide, barium chromate, zinc chromate and zinc dust are being used as pigments.

Dr. S. G. Clarke and W. N. Bradshaw, of the Armament Research Establishment, Ministry of Supply, reported some tests on the protective value of metallic coatings under sheltered conditions in marine atmospheres. Specimens of steel sheet carrying metallic coatings of various metals and thickness were exposed inside a ventilated box at a site on the north coast of Cornwall. After three years of exposure, no rusting had occurred on specimens with coatings of zinc or cadmium 0.3 mil thick; but specimens with an equally thick coating of tin, lead or lead-tin alloy had rusted severely; a similar coating of tin-zinc alloy had permitted moderate rusting. Specimens with a sprayed aluminium coating 3 mils thick were unrusted. The main conclusion to be drawn from the results is that, despite the present shortage of the metals concerned, a reasonable thickness of coating must be maintained if protection is to be ensured. An interesting observation was that all the corrosion products contained more sulphate than chloride, whereas the reverse holds true for sea salt.

F. Fancutt and Dr. J. C. Hudson described the researches of the Protective Coatings (Corrosion) Sub-Committee of the British Iron and Steel Research Association. Work on paints has shown the importance of correct surface preparation of steel for painting. The life of a given painting scheme was found to be four or five times greater on a properly prepared surface obtained by pickling or sandblasting than on the surface resulting from the common practice of weathering and hand-cleaning. Research on the formulation of paints for protecting steel against atmospheric corrosion is proceeding under the direction of a joint technical panel of the Sub-Committee with the paint industry. Several series of tests on priming paints are in progress. So far, the best results have been obtained from paints bound with linseed oil, partly because these paints naturally tend to give thicker films than paints in synthetic media. A paint pigmented with forty parts by weight of red lead, forty parts of white lead and twenty parts of asbestine and bound with linseed oil has proved equal in protective efficiency to a red lead in linseed oil priming-paint and has better can stability and better brushability. Recently a systematic study of the formulation of protective paints based on tars, pitches and bitumens has been undertaken.

Tests on metallic coatings have established that the protective value of a zine coating is mainly determined by its thickness and that the process of application, whether hot-dipping, cementation, electrodeposition or spraying, has little influence. A coating thickness of roughly 3 mils (say, $l \cdot 7 \mathrm{oz}$. of zinc per sq. ft. of surface) is needed to protect steel for five years in an industrial atmosphere like that of Sheffield. Approximately the same thickness of sprayed aluminium $(0 \cdot 8 \mathrm{oz}$. per sq. ft. $)$ will protect steel equally well.

Dr. P. T. Gilbert contributed a paper on the effect of impurities in the metal on the rate of corrosion of zinc and galvanized coatings in the atmosphere. Exposure tests made by the British Non-Ferrous Metals Research Association have shown that the usual impurities have little effect on the resistance of zinc to atmospheric corrosion. For example, the test duration to failure for a series of coatings containing appreciable percentages of aluminium, antimony, cadmium or tin, was essentially proportional to the coating weight and independent of the composition of the galvanizing bath; the addition of 2 per cent of copper did, however, reduce the corrosion of sheet zine by about 20 per cent. The corrosion-rate of zinc increased with time, and at the end of fourteen years of exposure was roughly twice the rate at the beginning. This increase is due to the roughening of the surface.

The afternoon session began with a paper by $D$. Bermane on difficulties encountered in open-air exposure testing. These fall into two categories: those associated with the organization of the tests, and those associated with the interpretation of the results. The former include the formulation of the paints, the choice of the exposure stations, and the number and shape of the specimens. The value of tests on painting schemes is greatly enhanced when full details of the paint formulations are known. There is no need to maintain a large number of stations, because the order of merit of different painting schemes does not vary greatly from one station to another. It would, however, be unwise to restrict tests to a single station, and the Belgian Commission has compromised by reducing its number of stations from eleven to four. Marked differences are -sometimes observed between the behaviours of duplicate specimens, so that it is desirable to conduct each test on four or five replicates. This course may lead to an unwieldy number of specimens ; some specimens have therefore been used for tests on more than one painting scheme. The shape of specimen is important. Hitherto the Belgian Commission has used a bent specimen consisting of vertical, inclined and horizontal surfaces, and has made observations on both the outer and the sheltered faccs. Unfortunately, the ratios of the lives of the paints on the six surfaces are not constant for different painting schemes, so that a specimen of simpler shape might be preferable. 
Difficulties in the interpretation of results have arisen from the use of the German scale DIN 4710 for assessing breakdown, mainly because the grades of this scale are too widely separated. Moreover, it is based solely on estimates of the rusting of the basis steel and takes no account of other important factors, such as chalking and cracking of the paint film.

In a second paper, M. Bermane compared the results of accelerated tests on paints by means of the Belgian Commission's cycle with those of a French cycle (Gaz de France), the weatherometer and the A.S.T.M. (American Society for Testing Materials) continuous salt-spray test, respectively. Of the four methods, only the French test and the Belgian test gave good correlation with outdoor tests.

R. St. J. Preston read a paper on the mechanism of the processes involved in atmospheric corrosion testing. Experiments at the Chemical Research Laboratory, Teddington, have shown that no direct reaction of any magnitude takes place between water vapour and iron at ordinary temperatures and that condensation of water must occur on the iron surface if appreciable corrosion is to result. This was demonstrated by an ingenious colour film showing tests on two similar steel specimens suspended in beakers containing a warm solution of sulphur dioxide. The bottom of one specimen dipped into the solution, so that the transfer of heat prevented condensation on it. This specimen remained unrusted. The other specimen, which was hung clear of the solution, experienced condensation and rusted rapidly.

General discussions were held at the end of both the morning and afternoon sessions, in which T. $H$. Turner, J. F. Kayser, Dr. J. E. O. Mayne, C. E. Richards, Dr. E. E. Longhurst, the authors of papers and others took part.

In the evening the Council of the Society of Chemical Industry entertained the Belgian visitors to dinner at the May Fair Hotel. After the loyal toast, Dr. W. H. J. Vernon proposed the health of the guests. In a simple and moving reply, Prof. Erculisse referred to the strong ties of gratitude and affection uniting Belgium and Great Britain. Here the dictum of Pascal-_"Le cour a des raisons que la raison ne comprend pas"- did not apply.

\section{JOHN LELAND, c. I506-52}

\section{By JOAN M. EYLES}

TOHN LELAND, famous as an antiquary and $\int$ topographer, died on April 18, 1552. For the previous five years his many manuscripts had lain untouched, since the melancholy day when Leland "by a most pitifull occasion fell about his wits". In fact, his detailed notes about his journeys through the length and breadth of England and Wales remained unpublished for a hundred and fifty years after his death, though they were copied and used by many later antiquaries. 'Then during $1710-12$, the "Itineraries" were edited and published by Thomas Hearne, the assiduous librarian of the Bodleian, in which many of Leland's manuscripts had found a worthy home. Nearly two centuries later, between 1907 and 1910, the "Itineraries" were re-published with maps and many annotations by Miss L. Toulmin Smith.
The "Itineraries" are a mine of information for the historian and antiquary, and most local historians quote Leland as their earliest and most interesting source of information, not only for descriptions of monuments and ancient buildings, but also for topographical details of rivers and streams, woods and cultivated ground. Less well known are his many observations concerning the mineral wealth of the country. Though few in number compared to his antiquarian notes, they provide valuable information for the economic historian and also have some interest for the geologist. Moreover, though Leland was no naturalist, he sometimes recorded the "commune fische" of different pools and lakes.

The exact date and place of Leland's birth is unknown, but he attended St. Paul's School, and graduated B.A. from Christ's College, Cambridge, in 1522. Later he studied at Oxford, and after two or three years there went to Paris, apparently with some sort of foreign scholarship. He returned to England about 1529, and in 1533 received a royal warrant from Henry VIII which permitted him "diligently to serche al the libraries and monasteries of this youre noble reaulme". While travelling about the country engaged on this task, Leland made the numerous notes which supply such a detailed description of England during the decade 1535-45. Interested in the local industries, he noted the quarries for stone and the workings for various minerals. He gave a long account of the salt works at Droitwich ; and in his description of Cornwall frequently referred to the many "tynne werkes", remarking how some of the streams were "clene chokid with the sandes" washed down from these works. He also noted such coal pits as he saw, including "pittes of se coles" at Wakefield and Gateshead, and others in Staffordshire, South Wales and Lancashire. His observations about the occurrence and working of coal are of considerable interest. Thus he noted: "The vaynes of the se coles ly sometyme open upon clives [cliffs] of the se, as round about Coket Island and other shores, and they be properly caullid.se coale; but they be not so good as the coles that are diggyd in the inner parte of the lande" ; and he added, "The craft is to cum to it with leste paine in depe digging", an observation which would no doubt be endorsed by the modern open-cast miner. Sometimes he noted the nature of the soil, whether chalky, gravelly or, as in "Venteland" (Monmouthshire), "of a darke reddische yerth ful of slaty stones". In a few places he noted fossils, such as the "myghty shells of great oysters turned in to stones" near Alderley in Gloucestershire, and "stones figurid like serpentes wounde into circles" (that is, ammonites) near Keynsham, Somerset. These may well be the first references to English fossils.

In an address that Leland presented to his royal master as a "Newe Yeares Gyfte" in 1546, he stated his intention of preparing, "if God sende me life to accomplish my beginninges", a map of the "worlde and impery of England", which would be engraved on a "quadrate table of silver". He also intended "such a description to make of youre reaulme yn writing, that it shaul be no mastery after, for the graver or painter to make a like by perfect exemple". By a strange coincidence, the first important engraved map of the British Isles was published at Rome in 1546. Its authorship has been attributed to the exiled George Lily, a prominent Catholic and son of William Lily, grammarian and Leland's former 